\title{
Impulsive sounds change European seabass swimming patterns: Influence of pulse repetition interval
}

\author{
Y.Y. Neo ${ }^{\text {a,* }}$, E. Ufkes ${ }^{a}$, R.A. Kastelein ${ }^{b}$, H.V. Winter ${ }^{c}$, C. ten Cate ${ }^{a}$, H. Slabbekoorn ${ }^{\text {a }}$ \\ ${ }^{a}$ Behavioural Biology, Institute of Biology Leiden (IBL), Leiden University, The Netherlands \\ ${ }^{\mathrm{b}}$ Sea Mammal Research Company (SEAMARCO), Harderwijk, The Netherlands \\ ${ }^{\mathrm{C}}$ Institute for Marine Resources $\mathcal{E}$ 'Ecosystem Studies (IMARES) IJmuiden, Wageningen UR, The Netherlands
}

\section{A R T I C L E I N F O}

\section{Article history:}

Received 16 April 2015

Revised 9 June 2015

Accepted 11 June 2015

Available online 15 June 2015

\section{Keywords:}

Dicentrarchus labrax

Sound temporal structure

Anthropogenic noise

Fish behaviour

Habituation

\begin{abstract}
A B S T R A C T
Seismic shootings and offshore pile-driving are regularly performed, emitting significant amounts of noise that may negatively affect fish behaviour. The pulse repetition interval (PRI) of these impulsive sounds may vary considerably and influence the behavioural impact and recovery. Here, we tested the effect of four PRIs (0.5-4.0 s) on European seabass swimming patterns in an outdoor basin. At the onset of the sound exposures, the fish swam faster and dived deeper in tighter shoals. PRI affected the immediate and delayed behavioural changes but not the recovery time. Our study highlights that (1) the behavioural changes of captive European seabass were consistent with previous indoor and outdoor studies; (2) PRI could influence behavioural impact differentially, which may have management implications; (3) some acoustic metrics, e.g. $\mathrm{SEL}_{\mathrm{cum}}$, may have limited predictive power to assess the strength of behavioural impacts of noise. Noise impact assessments need to consider the contribution of sound temporal structure.
\end{abstract}

(C) 2015 Elsevier Ltd. All rights reserved.

\section{Introduction}

The ever increasing global energy demand has led to extensive exploitation of seas and oceans for both fossil and sustainable energy resources (EIA, 2013). Related human activities, such as seismic surveys and offshore constructions for wind farms and oil rigs, generate a substantial amount of noise in the underwater environment. This introduction of anthropogenic noise into the underwater acoustic scene may post a threat to aquatic life, including fish, causing a range of negative effects, from physical injuries in close range, to behavioural changes further away from the sound sources (Popper and Hastings, 2009a,b; Slabbekoorn et al., 2010). To ensure the stability of marine ecosystems under increased pressure of ocean exploitation, it is important to understand whether and how underwater anthropogenic noise may affect fish behaviour, which in turn may have consequences on fish populations.

Whether behavioural changes will result in negative fitness consequences, depends partly on whether fish habituate to the noise exposures and recover from the changes. However, behavioural observations in previous noise impact studies generally did not last long enough to show recovery after initial behavioural changes (Gerlotto and Fréon, 1992; Handegard et al., 2003;

\footnotetext{
* Corresponding author.

E-mail address: y.y.neo.2@umail.leidenuniv.nl (Y.Y. Neo).
}

Doksæter et al., 2012; Fewtrell and McCauley, 2012; but see Neo et al., 2014). Moreover, a recovery or a decrease in response does not necessarily denote habituation, where the animals hear selectively while filtering out repeated or irrelevant sound signals in the background (Rankin et al., 2009). A decrease in behavioural response could also be attributed to (1) sensory adaptation, i.e. the sensitivity of the hearing organs is reduced by loud exposures, leading to temporary threshold shift (TTS), or (2) motor fatigue, i.e. animals become unresponsive due to exhaustion (Domjan, 2010). It is crucial to determine the mechanism of such behavioural recovery since the different mechanisms vary in their ecological implications.

Underwater noise impact assessments are complex also because anthropogenic noise shows a variety of amplitudinal, spectral and temporal variations. Of these, the temporal structure of sound is rarely studied, even though it may play a crucial role in triggering behavioural response in fish (Nelson and Johnson, 1972; Neo et al., 2014). For example, Neo et al., 2014 showed that European seabass (Dicentrarchus labrax) recovered more slowly from impulsive sounds than from continuous sounds (despite the former having lower accumulated sound pressure level), after exhibiting consistent initial behavioural changes upon noise exposures. Considering that impulsive sounds differ in various temporal features, there is a need for systematic studies addressing other temporal parameters, such as pulse repetition interval, pulse 
repetition regularity, pulse duration and pulse shape (including rise time).

Among these temporal parameters, pulse repetition interval (PRI), which can also be expressed in pulse repetition rate (PRR, where PRR $=1 / P R I$ ), is rather variable among the current practices in pile driving and seismic surveys. PRI generally varies between 1-4 s (Matuschek and Betke, 2009) for pile driving and 5-15 s (McCauley et al., 2000) for seismic surveys. Different PRIs have been shown to influence the habituation rate to repeated sound stimuli in zebrafish and rats (Chanin et al., 2012; Davis, 1970). However, it is unclear if PRI also contributes to fish habituation to impulsive anthropogenic sound exposures, such as pile driving and seismic shootings.

In this study, we used a similar setup as in Neo et al., 2014 to answer two questions: (1) How do impulsive sounds of different PRIs $(0.5 \mathrm{~s}, 1.0 \mathrm{~s}, 2.0 \mathrm{~s}, 4.0 \mathrm{~s})$ affect the swimming patterns and behavioural recovery of European seabass? (2) Can the behavioural recovery be attributed to habituation? We expected larger PRIs to prolong the behavioural recovery and the recovery be attributed to habituation.

\section{Materials and methods}

\subsection{Animal maintenance}

The European seabass (mixed sex; $20-25 \mathrm{~cm}$ in total body length) came from a commercial hatchery (Ecloserie Marine, Gravelines, France) and were kept in four round holding tanks (diameter: $2.2 \mathrm{~m}$; depth: $1 \mathrm{~m}$ ) before and after the test trials at the Sea Mammal Research Company (SEAMARCO) in Wilhelminadorp, The Netherlands. Water was refreshed continuously with a recirculating system connected to the nearby Oosterschelde marine inlet and the water temperature varied from 4 to $12{ }^{\circ} \mathrm{C}$ throughout the experimental period (May-June 2013). Fish were fed pellets (Le Gouessant Aquaculture, Lamballe, France) every other day based on a temperature-dependent prescription. All experiments were performed in accordance with the Dutch Experiments on Animals Act and approved by the Animal Experiments Committee at Leiden University (DEC no: 13023).

\subsection{Experimental arena}

The experiment was conducted in a large outdoor rectangular basin $(7 \times 4 \times 2 \mathrm{~m})$ equipped with a water recirculating system at SEAMARCO. During the exposure trials, fish were put in a white nylon net enclosure $(4 \times 1.6 \times 2 \mathrm{~m})$ to ensure full coverage by an underwater video camera for observation (Fig. 1). A white tarp was placed at the bottom and in the background to ensure sufficient contrast in video images, without disrupting the normal swimming behaviour of the fish. Beside the basin, there was a

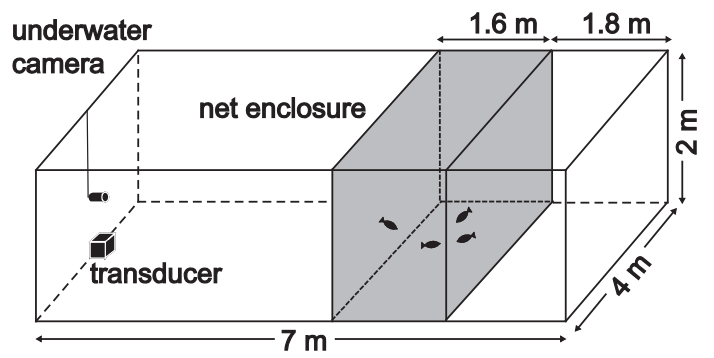

Fig. 1. Experimental basin at SEAMARCO. Shaded area is the net enclosure with restricted swimming space for four fish. research cabin containing sound generating and video monitoring equipment.

\subsection{Treatment series}

We exposed the fish to a series of four regularly repeated impulsive sound treatments differing in PRI: $0.5 \mathrm{~s}, 1.0 \mathrm{~s}, 2.0 \mathrm{~s}$ and $4.0 \mathrm{~s}$ (Table 1). The pulse duration of all the treatments was the same, which was around $0.15 \mathrm{~s}$ (Fig. 2a). The pulses were created in Adobe Audition 3.0 using filtered brown noise (band-passed: $200-1000 \mathrm{~Hz}$; matching the hearing range of European seabass) and played back with an underwater transducer (LL-1424HP, Lubell Labs, Columbus, US) from a laptop through a power amplifier (Macro-tech $5000 \mathrm{VZ}$, Crown Audio, Elkhart, US). The whole experimental arena had a very homogenous sound pressure field during the playback of broadband sounds (Neo et al., 2014). The average root-mean-square sound pressure level ( $\mathrm{SPL}_{\mathrm{rms}}$ ) before the exposure (ambient) in the experimental basin was $104 \mathrm{~dB}$ re $1 \mu \mathrm{Pa}$, which was comparable to the ambient noise levels of our measurements in the Oosterschelde marine inlet. To quantify the amplitude level of the impulsive sound treatments, single-strike sound exposure level ( $\left.\mathrm{SEL}_{\mathrm{ss}}\right)$ and zero-to-peak sound pressure level $\left(\mathrm{SPL}_{z-\mathrm{p}}\right)$ were measured (Table 1$)$. The amplitude levels were chosen to represent received level of pile driving at a range of around $50-100 \mathrm{~km}$ according to ideal cylindrical spreading. Spectral investigation confirmed that most of the sound energy of the pulses was concentrated between 200 and $1000 \mathrm{~Hz}$ (Fig. 2b).

Particle motion may be perceptually dominant in European seabass hearing (Popper and Fay, 2011), but we were unable to measure this. However, we believe that the lack of this information is not a concern in this study, since our aim was not to assess absolute threshold levels that can be extrapolated to outside conditions. Our main interest was to compare the effects of PRI on behavioural response while keeping other acoustic parameters constant.

\subsection{Experimental set-up}

We tested twelve groups of four fish, where each group was exposed to all four treatments $(N=12,48$ fish). The order of the treatments per fish group followed an incomplete counterbalanced design (12 of 24 possible orders), to minimise the potential 'carry-over' effect due to sequential exposures. At least $17 \mathrm{~h}$ prior to the trials, each fish group was transferred to the experimental basin to allow acclimatisation. $30 \mathrm{~min}$ before each trial, the transducer and the lights above the experimental basin were turned on. We conducted two trials per day: one in the morning and one in the afternoon, with a break of at least three hours in between. There was no external anthropogenic noise or disturbance near the study area during the trials. The trials consisted of $10 \mathrm{~min}$ of pre-exposure silence and $60 \mathrm{~min}$ of sound exposure. Based on pilot and previous studies (Neo et al., 2014), we expected the fish behaviour to recover within $60 \mathrm{~min}$ of sound exposure. Right after the

Table 1

Relevant acoustic parameters of the four sound treatments: pulse repetition interval (PRI), pulse repetition rate (PRR), exposure duration, average zero-to-peak sound pressure level $\left(\mathrm{SPL}_{\mathrm{z}-\mathrm{p}}\right)$, average single-strike sound exposure level $\left(\mathrm{SEL}_{\mathrm{ss}}\right)$, number of pulse and average cumulative sound exposure level ( $\left.\mathrm{SEL}_{\mathrm{cum}}\right)$.

\begin{tabular}{llllllll}
\hline $\begin{array}{l}\text { Treatment } \\
\text { no }\end{array}$ & $\begin{array}{l}\text { PRI } \\
(\mathrm{s})\end{array}$ & $\begin{array}{l}\text { PRR } \\
\left(\mathrm{s}^{-1}\right)\end{array}$ & $\begin{array}{l}\text { Duration } \\
(\mathrm{min})\end{array}$ & $\begin{array}{l}\mathrm{Avg} \\
\mathrm{SPL}_{\mathrm{z}-\mathrm{p}}\end{array}$ & $\begin{array}{l}\text { Avg } \\
\mathrm{SEL}_{\mathrm{ss}}\end{array}$ & $\begin{array}{l}\text { Pulse } \\
\text { no }\end{array}$ & $\begin{array}{l}\text { Avg } \\
\mathrm{SEL}_{\text {cum }}\end{array}$ \\
\hline 1 & 0.5 & 2.00 & 60 & 158 & 140 & 7200 & 179 \\
2 & 1.0 & 1.00 & 60 & 158 & 140 & 3600 & 176 \\
3 & 2.0 & 0.50 & 60 & 158 & 140 & 1800 & 173 \\
4 & 4.0 & 0.25 & 60 & 158 & 140 & 900 & 170 \\
\hline
\end{tabular}


(a) Time domain waveform

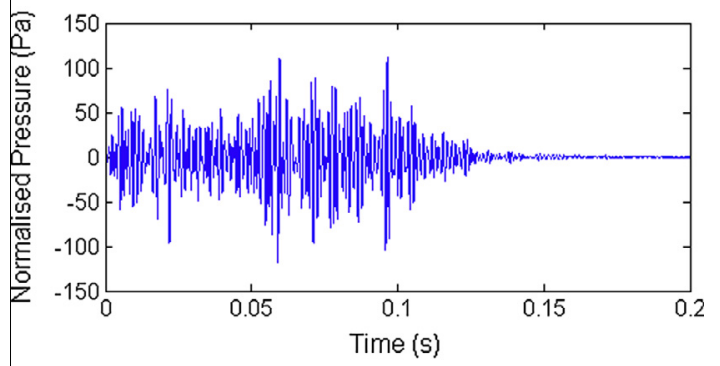

(b) Power density spectra

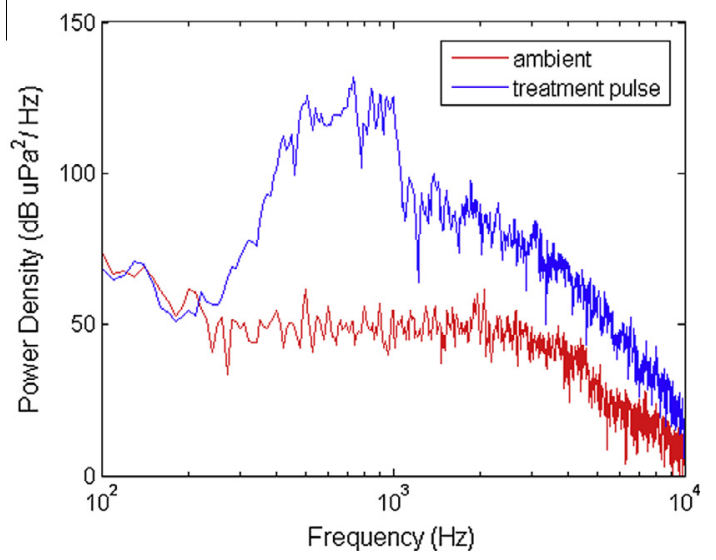

Fig. 2. (a) Time domain waveform of a single pulse used in the treatments and (b) power density spectra of the same pulse and the ambient noise before the playback of the pulse.

playback of the 60-min treatment sound, a 2-s $600 \mathrm{~Hz}$ tone $\left(\mathrm{SEL}_{\mathrm{ss}}=156 \mathrm{~dB}\right.$ re $1 \mu \mathrm{Pa}, \mathrm{SPL}_{\mathrm{z}-\mathrm{p}}=157 \mathrm{~dB}$ re $\left.1 \mu \mathrm{Pa}\right)$ was played back to test for stimulus specificity of the behavioural recovery, which was to demonstrate that the recovery was due to habituation and not sensory adaptation or motor fatigue (Rankin et al., 2009). The fish were expected to show startle response again upon presentation of the tone, if they had only habituated to the repeated impulsive treatment sound and could still hear and react to a novel sound stimulus.

\subsection{Behavioural observation E' analysis}

The fish were video-recorded during the entire exposure sessions ( $10 \mathrm{~min}$ before, $60 \mathrm{~min}$ during and $10 \mathrm{~s}$ after sound exposure). The full video recordings were analysed with tracking software, Logger Pro 3.8.5.1 (Vernier Software \& Technology, Beaverton, US), with manual placement of all fish coordinates every second. The coordinates were then used to calculate the swimming speed, the swimming depth and the group cohesion (average inter-individual distance).

\subsection{Statistics}

To test for the change in swimming depth and group cohesion during the trials, we conducted two-way repeated measures ANOVAs comparing three 5-min bins of exposure sequence from our data set: $5 \mathrm{~min}$ right before sound exposure ('before'), the first 5 min of exposure ('start') and the last 5 min of exposure ('end'). The bin length was chosen based on a previous study with comparable setup (Neo et al., 2014). Both exposure sequence and treatment were treated as within-subject (repeated) factors. If sphericity cannot be assumed, Huynh-Feldt correction was used.
To test for the change in swimming speed, we used the same procedure but the bins were $10 \mathrm{~s}$ instead of $5 \mathrm{~min}$, in order to capture the transient nature of speed change. The order effect was also tested in the model as a covariate but was subsequently excluded when it showed no correlation.

To understand the interaction of the two factors in the previous test and find out if the behavioural changes varied systematically across treatments of different PRIs, we performed repeated measures linear contrast analyses to compare the difference before and at the start of exposure, as well as before and at the end of exposure for the three parameters above. This statistical test has a higher power than omnibus ANOVA tests, given that we had $a$ priori expectation that our variables correlated in a linear manner. We also performed one-sample $t$-tests to see if each difference mentioned was significantly larger than 0 .

We also analysed the recovery time of the behavioural changes, which was defined as the time that the fish took to revert back to the pre-exposure swimming depth and group cohesion. The 5-min average of swimming depth and group cohesion before exposure was used as a baseline to compare with the 5-min moving averages (shifting forward every second) during exposure, to see when the baseline was reached again. If the baseline was not reached by the end of the trial, the recovery time was counted as $60 \mathrm{~min}$ (occurrence frequency: 2/48 for swimming depth and 2/48 for group cohesion). The recovery time of swimming speed was analysed in the same manner but with 10-s averages. To compare the effect of different treatments on recovery time, we performed non-parametric Friedman test, which accounted for the repeated nature of the treatments. To demonstrate that the behavioural recovery observed was due to habituation and not sensory adaptation or motor fatigue, we compared 10-s bins of swimming speed before and after the start of sound treatments, and before and after the playback of a $600-\mathrm{Hz}$ tone right after the sound treatments.

\section{Results}

The fish significantly increased in swimming speed (two-way rANOVA: $F_{2,22}=12.108, P<0.001$; Bonferroni-Holm post-hoc: 'before' vs 'start', $P=0.008$ ) and swam to significantly greater depth at the start of the exposure (two-way rANOVA: $F_{2,22}=28.121$, $P<0.001$; Bonferroni-Holm post-hoc: 'before' vs 'start', $P=0.005$ ) in significantly tighter shoals (two-way rANOVA: $F_{2,22}=6.886$, $P=0.005$; Bonferroni-Holm post-hoc: 'before' vs 'start', $P<0.05$ ). By the end of the exposure, swimming speed and group cohesion recovered to pre-exposure level (Bonferroni-Holm post-hoc: 'before' vs 'end', $P=1.000 \& P=0.454$ respectively) but swimming depth became even shallower than pre-exposure level (Bonferroni-Holm post-hoc: 'before' vs 'end', $P<0.01$ ). The analysis also showed that for swimming depth, there was a non-significant trend on the interaction between PRI and the 5-min exposure sequence (Huynh-Feldt corrected two-way rANOVA: $\left.F_{4.7,51.8}=2.136, P=0.079\right)$.

The magnitude of change from before to the start of exposure did not vary systematically across the four PRIs for swimming speed, swimming depth and group cohesion (linear contrast analysis: $F_{1,11}=1.232, P=0.291, F_{1,11}=0.015, P=0.904 ; F_{1,11}=0.063$, $P=0.128$ respectively) (Fig. 3 ). When testing for PRI-specific effects in the difference of swimming speed, the difference was significantly larger than 0 for PRI $1.0 \mathrm{~s}$ and $4.0 \mathrm{~s}$ (one-sample $t$-test: $t_{11}=3.388, P=0.006 ; t_{11}=2.666, P=0.022$ respectively) but a non-significant trend for PRI $0.5 \mathrm{~s}$ and $2.0 \mathrm{~s}$ (one-sample $t$-test: $t_{11}=1.921, P=0.081 ; t_{11}=1.832, P=0.094$ respectively). For swimming depth, the difference was significant for all the treatments (one-sample $t$-test: $-3.944 \leqslant t_{11} \leqslant-2.285$, all $P \mathrm{~s}<0.05$ ). For group cohesion, only PRI $1.0 \mathrm{~s}$ was significantly larger than 0 (one-sample 
(a) Swimming speed | before - start

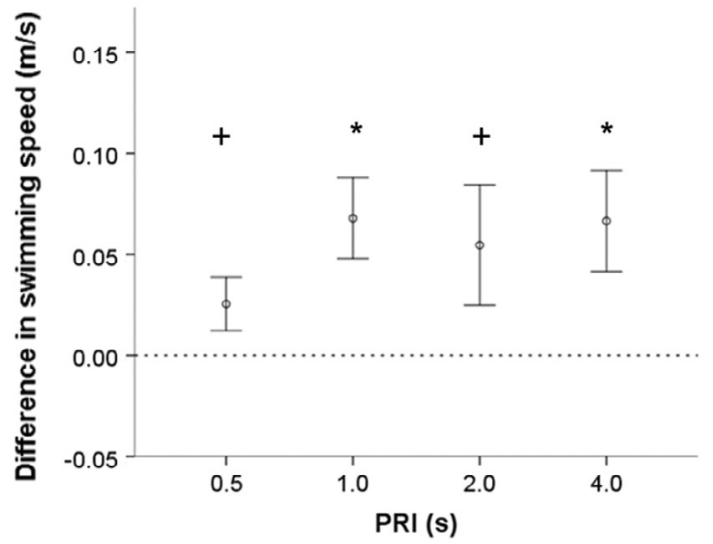

(c) Swimming depth | before - start

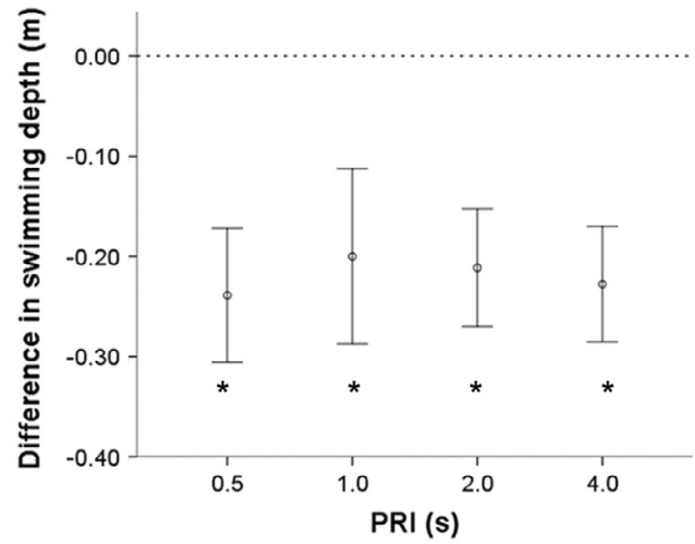

(e) Group cohesion | before - start

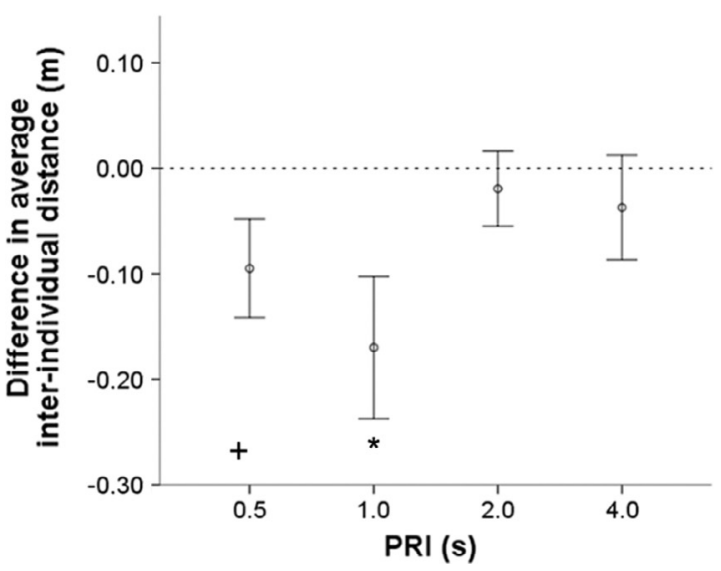

(b) Swimming speed | before - end

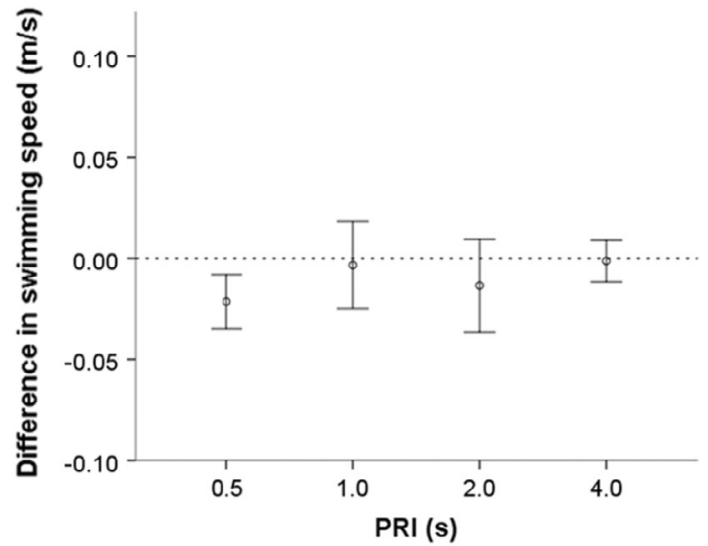

(d) Swimming depth | before - end

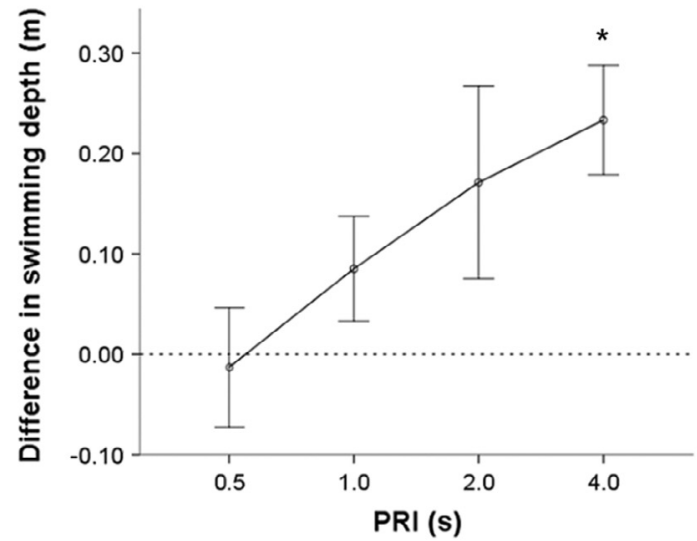

(f) Group cohesion | before - end

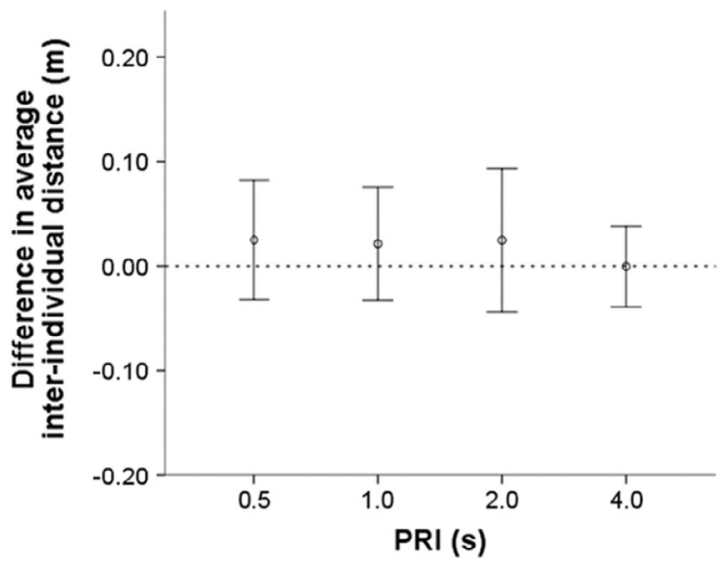

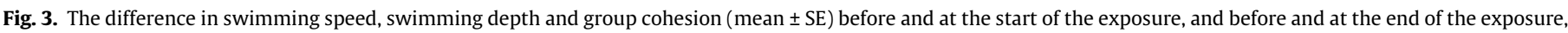

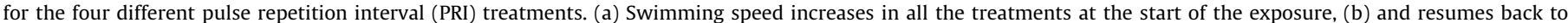

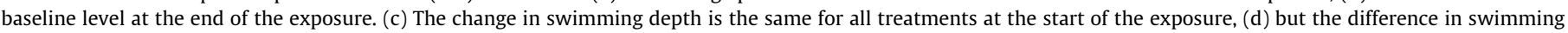

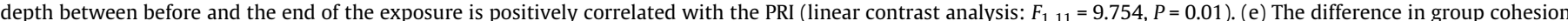

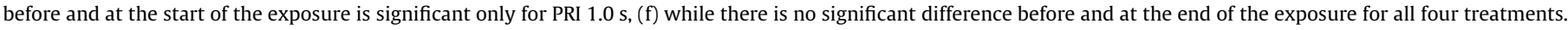
An asterisk $(*)$ denotes a significant difference from $0(P \leqslant 0.05)$ and a plus $(+)$ denotes a non-significant trend $(0.05<P \leqslant 0.1)$.

$t$-test: $\left.t_{11}=-2.523, P=0.028\right)$, while PRI $0.5 \mathrm{~s}$ was a non-significant trend (one-sample $t$-test: $t_{11}=-2.035, P=0.067$ ).

For the difference between before and the end of the exposure, swimming speed and group cohesion was the same across all treatments (linear contrast analysis: $F_{1,11}=1.021, P=0.334$; $F_{1,11}=0.133, P=0.722$ respectively), but swimming depth showed a significant positive linear effect (linear contrast analysis:
$\left.F_{1,11}=9.754, P=0.01\right)$. The difference with baseline ranged from no significant difference for PRI $0.5 \mathrm{~s}$ (one-sample $t$-test: $t_{11}=-0.218, P=0.831$ ), $1.0 \mathrm{~s}$ (one-sample $t$-test: $t_{11}=-0.218$, $P=0.831$ ) and $2.0 \mathrm{~s}$ (one-sample $t$-test: $t_{11}=-1.630, P=0.131$ ), to a significant difference of $0.23 \pm 0.19$ (SD) $\mathrm{m}$ for PRI $4.0 \mathrm{~s}$ (one-sample $t$-test: $t_{11}=4.285, P=0.001$ ). 
We found that the fish habituated to the treatment sounds within an hour (Fig. 4), but the habituation time did not vary significantly among all treatments, for swimming speed (Friedman test: $X_{3}^{2}=5.625, P=0.131$ ), swimming depth (Friedman test: $X_{3}^{2}=2.806, \quad P=0.423$ ) and group cohesion (Friedman test: $X_{3}^{2}=1.216, P=0.749$ ). When comparing the swimming speeds before and after the first pulse of sound treatments, and before and after the playback of a $600-\mathrm{Hz}$ tone right after the sound treatments, both exposure types resulted in a rapid increase in swimming speed (startle response) (two-way rANOVA: $F_{1,46}=32.377, P<0.001$ for exposure sequence; $F_{1,46}=1.997, P=0.164$ for exposure type; $F_{1,46}=0.669, P=0.418$ for the interaction of the two factors),

\section{(a) Recovery of swimming speed}

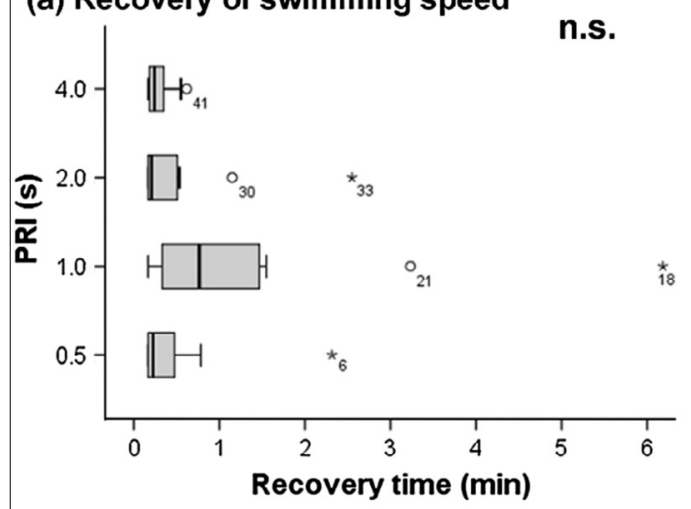

(b) Recovery of swimming depth

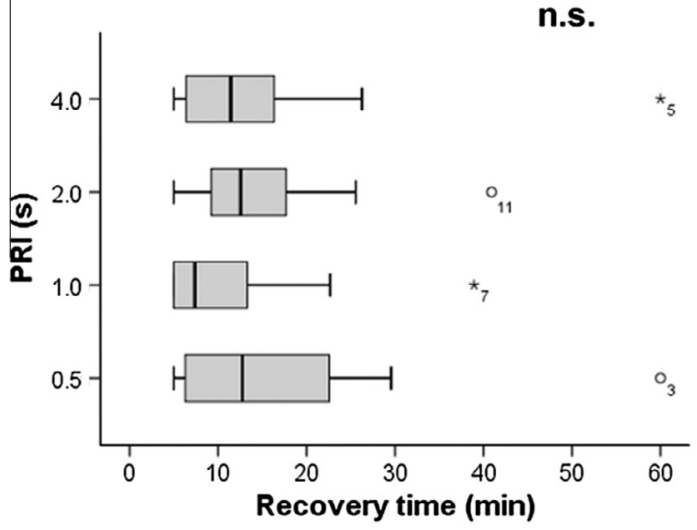

(c) Recovery of group cohesion

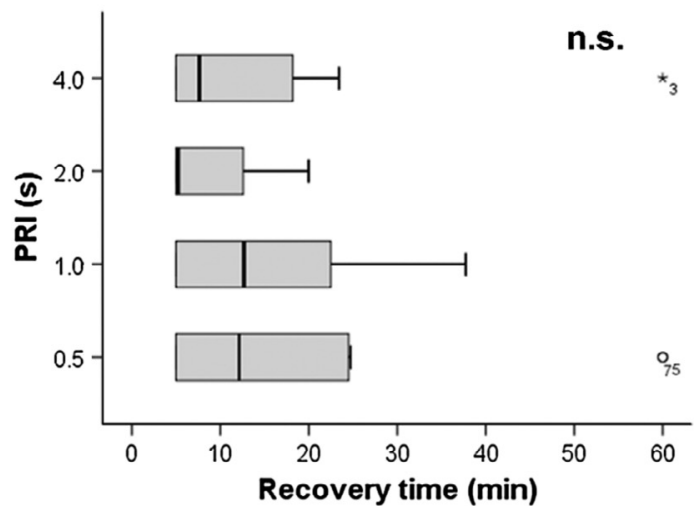

Fig. 4. Boxplots showing the recovery time of (a) swimming speed, (b) swimming depth and (c) group cohesion for the four pulse repetition interval (PRI) treatments. The fish habituate to the sound exposure within the same time for the four treatments. indicating that at the end of the trials, the fish could still hear the tone and react to it to the same degree as to the treatment sound at the start of the trials (Fig. 5). The PRI of the treatment did not influence the speed change caused by the 2-s tone (two-way rANOVA: $\quad F_{1,44}=16.192, \quad P<0.001$ for exposure sequence; $F_{1,44}=0.147, P=0.931$ for the interaction of exposure sequence and PRI).

\section{Discussion}

The European seabass in this study swam to the bottom of the basin and formed tighter shoal upon exposure to impulsive sounds. All treatments seemed to be equally effective in eliciting an initial response of increased swimming speed and bottom diving, independent of the PRI, except for group cohesion, which was less affected by the slower than the faster pulse rates. Over time, they recovered by swimming higher up in the water column and shoaling less tightly again. Recovery occurred at the same rate regardless of the PRI of the sound treatments. While swimming speed and group cohesion reverted back to the baseline level and remained there till the end of the exposure, swimming depth went beyond baseline level by the end of the exposure depending on the PRI of the sound treatments: the longer the PRI, the shallower the fish swam. We also demonstrated that the behavioural recovery could be attributed to habituation to the sound treatments.

\subsection{Immediate behavioural changes}

The startle response, bottom diving and shoaling behaviour observed at the start of sound exposure in this study mirror a previous study using larger European seabass $(35 \mathrm{~cm})$ in a smaller experimental enclosure (Neo et al., 2014), although the magnitude of changes was smaller in the current study. The observed behavioural changes were also consistent with several other studies conducted on other captive or wild species using various sound sources (Doksæter et al., 2012; Fewtrell and McCauley, 2012; Gerlotto and Fréon, 1992; Handegard and Tjøstheim, 2005; Slotte et al., 2004). These behaviours have typically been associated with fright and anxiety in neurophysiological studies (Cachat et al.,

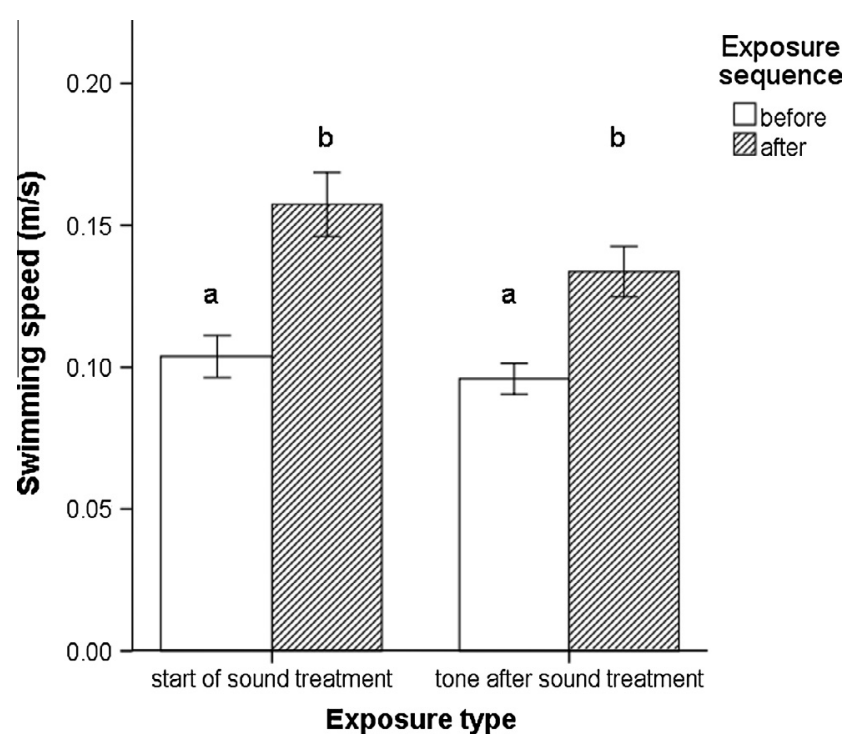

Fig. 5. Average swimming speed $( \pm S E)$ before and after the exposure of two different acoustic stimuli. The swimming speed changes in the same way during the playback of $600 \mathrm{~Hz}$ tone compared to the playback of sound treatments, indicating that the fish could still hear and react to a novel acoustic stimulus after having habituated to the treatment exposure. 
2010; Eaton et al., 1977; Maximino et al., 2010), and each of them is likely related to specific stress-related contexts (Neo et al., 2014). These behavioural changes may incur short-term energetic costs to the fish, but it is still unknown if they will lead to disruptions of other important behaviours and have long-term consequences on fish populations.

\subsection{Effects of pulse repetition interval}

Contrary to our expectation, PRI of sound exposure had no influence on the habituation rate of the fish. This may be either because the range of PRIs tested in this study was not large enough to provide sufficient resolution to yield an observable difference in habituation rate, or because our setup did not allow inter-pulse spontaneous recovery, like in other studies that tested different PRIs on sound habituation (Chanin et al., 2012; Davis, 1970). Nevertheless, our fish appeared to perceive the difference of the four PRIs tested, since they changed their group cohesion at the start of the sound exposure depending on the PRI and showed a PRI-dependant swimming depth difference at the end of the sound exposure. The correlation of PRI and 'post-habituation' swimming depth suggests that PRI of impulsive sound exposure can cause fish swimming behaviour to deviate from baseline level, although the underlying mechanisms are still unknown.

One possible explanation is that the fish swam higher up in the water column due to reduced general wariness as a result of attentional shift caused by the constant input of the habituated sounds, despite immediate stress-related response at the onset of exposure (Cachat et al., 2010; Chan et al., 2010; Maximino et al., 2010). Although the fish might be in a lower anxiety state, there could be other negative consequences during noise exposure, such as masking of important acoustic cues and distraction from potential predators and prey (Chan et al., 2010; Purser and Radford, 2011). Another explanation is that the observation was in fact habituation that proceeded beyond the baseline and reached a different asymptotic level (Grissom and Bhatnagar, 2009; Rankin et al., 2009; Thompson and Spencer, 1966). This implies that the treatments with larger PRIs in our study resulted in longer habituation time, which is in agreement with the literature (Rankin and Broster, 1992; Rankin et al., 2009). However, it is unclear if the elevated swimming depth would eventually revert back to the baseline, as this potential recovery could not be determined in our experimental setup, where a $600 \mathrm{~Hz}$ tone was played right after the treatment trials and the fish readily dived to the bottom regardless of the PRIs.

\subsection{Implications for noise impact assessments}

Our findings suggest the potential contribution of PRI of impulsive sound exposure in changing the swimming patterns and perhaps the state of wariness of fish during sound exposures. This effect was seen at the start of the exposure for group cohesion and the end of the exposure for swimming depth, but not for the habituation rate to the sound exposure. However, the mechanisms of the observed effects are unclear, which renders the interpretation problematic. Therefore, caution is necessary when translating this finding to management strategies.

Nevertheless, our results suggested that the treatment with $0.5 \mathrm{~s}$ PRI had the least impact on fish swimming depth compared to other treatments with larger PRIs, even though its $\mathrm{SEL}_{\text {cum }}$ and number of strikes were the highest. This implies that some standard metrics such as $\mathrm{SEL}_{\text {cum }}$ and the number of pulse strikes may have limited predictive power for assessing potential behavioural impacts of impulsive sounds (Handegard et al., 2013). This is in agreement with the results of Neo et al. (2014), where impulsive sound treatments prolonged the behavioural recovery of
European seabass for twice as long compared to continuous sound treatments (with about double the $\mathrm{SEL}_{\mathrm{cum}}$ ). In view of this, our results agreed with Halvorsen et al. (2012), who investigated the thresholds for impulsive sounds to cause barotrauma injuries in Chinook salmon (Oncorhynchus tshawytscha), in rejecting the 'Equal Energy Hypothesis', which states that the same amount of acoustic energy will cause the same level of impact severity, regardless of how the energy is distributed in time (Stadler and Woodbury, 2009; Woodbury and Stadler, 2008).

In regard to relevant metrics for noise assessment on behavioural impacts, we believe that the qualitative characteristics of sound, such as various temporal structure parameters, including PRI, may be very useful (Neo et al., 2014). Therefore, more temporal parameters, such as pulse repetition regularity, pulse duration and pulse shape, still need to be studied, so that some well-grounded quantification metrics and assessment methods can eventually be developed, which will provide practical information to inform management decisions regarding anthropogenic noise impacts.

\section{Conclusion}

Our study suggests that different PRIs of impulsive sounds may affect the immediate or delayed behavioural changes of fish differentially, without influencing the rate of the behavioural recovery. It is unclear whether these differences in behavioural changes would matter when it comes to the fitness consequences of the fish, especially in the wild. Nevertheless, despite the uncertainties, our findings provide insights into the relative impact strength of PRI, and highlight the importance of future studies conducted in the field, examining the temporal variations of sound exposures in assessing impact severity.

\section{Acknowledgements}

We thank Loes Bolle from IMARES for her constructive feedback on the project. Our appreciation also goes to Ewout Blom for arranging the purchase and transport of the fish to SEAMARCO. We are also grateful to personnel from SEAMARCO for helping to take care of the fish. Y.Y.N. was supported by a ZKO grant (839.10.522) from the Netherlands Organization of Scientific Research (NWO).

\section{References}

Cachat, J., Stewart, A., Grossman, L., Gaikwad, S., Kadri, F., Chung, K.M., Wu, N., Wong, K., Roy, S., Suciu, C., Goodspeed, J., Elegante, M., Bartels, B., Elkhayat, S., Tien, D., Tan, J., Denmark, A., Gilder, T., Kyzar, E., Dileo, J., Frank, K., Chang, K., Utterback, E., Hart, P., Kalueff, A.V., 2010. Measuring behavioral and endocrine responses to novelty stress in adult zebrafish. Nat. Protoc. 5, 1786-1799.

Chan, A.A.Y.-H., Giraldo-Perez, P., Smith, S., Blumstein, D.T., 2010. Anthropogenic noise affects risk assessment and attention: the distracted prey hypothesis. Biol. Lett. 6, 458-461.

Chanin, S., Fryar, C., Varga, D., Raymond, J., Kyzar, E., Enriquez, J., Bagawandoss, S., Gaikwad, S., Roth, A., Pham, M., Zapolsky, I., Bruce, I., Hester, J., Green, J., Desmond, D., Stewart, A.M., Kalueff, A.V., 2012. Assessing startle responses and their habituation in adult zebrafish. Zebrafish Protoc. Neurobehav. Res. Neurometh. 66, 287-300.

Davis, M., 1970. Effects of interstimulus interval length and variability on startleresponse habituation in the rat. J. Comp. Physiol. Psychol. 72, 177-192.

Doksæter, L., Handegard, N.O., Godø, O.R., Kvadsheim, P.H., Nordlund, N., 2012 Behavior of captive herring exposed to naval sonar transmissions (1.0-1.6 kHz) throughout a yearly cycle. J. Acoust. Soc. Am. 131, 1632-1642.

Domjan, M., 2010. The Principles of Learning and Behaviour, sixth ed. Wadsworth, Cengage Learning, Belmont, CA.

Eaton, R.C., Bombardieri, R.A., Meyer, D.L., 1977. The Mauthner-initiated startle response in teleost fish. J. Exp. Biol. 66, 65-81.

EIA, 2013. International Energy Outlook 2013. Washington.

Fewtrell, J.L., McCauley, R.D., 2012. Impact of air gun noise on the behaviour of marine fish and squid. Mar. Pollut. Bull. 64, 984-993.

Gerlotto, F., Fréon, P., 1992. Some elements on vertical avoidance of fish schools to a vessel during acoustic surveys. Fish. Res. 14, 251-259. 
Grissom, N., Bhatnagar, S., 2009. Habituation to repeated stress: get used to it. Neurobiol. Learn. Mem. 92, 215-224.

Halvorsen, M.B., Casper, B.M., Woodley, C.M., Carlson, T.J., Popper, A.N., 2012 Threshold for onset of injury in Chinook salmon from exposure to impulsive pile driving sounds. PLoS ONE 7, e38968.

Handegard, N.O., Michalsen, K., Tjøstheim, D., 2003. Avoidance behaviour in cod (Gadus morhua) to a bottom-trawling vessel. Aquat. Living Resour. 16, 265270.

Handegard, N.O., Tjøstheim, D., 2005. When fish meet a trawling vessel: examining the behaviour of gadoids using a free-floating buoy and acoustic split-beam tracking. Can. J. Fish. 2422, 2409-2422.

Handegard, N.O., Tronstad, T.V., Hovem, J.M., 2013. Evaluating the effect of seismic surveys on fish-the efficacy of different exposure metrics to explain disturbance. Can. J. Fish. Aquat. Sci. 70, 1271-1277.

Matuschek, R., Betke, K., 2009. Measurements of construction noise during pile driving of offshore research platforms and wind farms. In: Boone, M. (Ed.), NAG DAGA International Conference on Acoustics 2009. Curran Associates Inc, Rotterdam, pp. 262-265.

Maximino, C., de Brito, T.M., da Silva Batista, A.W., Herculano, A.M., Morato, S., Gouveia Jr, A., 2010. Measuring anxiety in zebrafish: a critical review. Behav. Brain Res. 214, 157-171.

McCauley, R., Fewtrell, J., Duncan, A.J., Jenner, C., Jenner, M.-N., Penrose, J.D., Prince, R.I.T., Adhitya, A., Murdoch, J., McCabe, K., 2000. Marine seismic surveys: a study of environmental implications. Aust. Pet. Prod. Explor. Assoc. J., 692-708

Nelson, D., Johnson, R., 1972. Acoustic attraction of Pacific reef sharks: effect of pulse intermittency and variability. Comp. Biochem. Physiol. Part A Physiol. 42, 85-95.

Neo, Y.Y., Seitz, J., Kastelein, R.A., Winter, H.V., ten Cate, C., Slabbekoorn, H., 2014 Temporal structure of sound affects behavioural recovery from noise impact in European seabass. Biol. Conserv. 178, 65-73.

Popper, A.N., Fay, R.R., 2011. Rethinking sound detection by fishes. Hear. Res. 273, 25-36.
Popper, A.N., Hastings, M.C., 2009a. The effects of anthropogenic sources of sound on fishes. J. Fish Biol. 75, 455-489.

Popper, A.N., Hastings, M.C., 2009b. The effects of human-generated sound on fish. Integr. Zool. 4, 43-52.

Purser, J., Radford, A.N., 2011. Acoustic noise induces attention shifts and reduces foraging performance in three-spined sticklebacks (Gasterosteus aculeatus). PLoS ONE 6, e17478.

Rankin, C.H., Abrams, T., Barry, R.J., Bhatnagar, S., Clayton, D.F., Colombo, J., Coppola, G., Geyer, M.A, Glanzman, D.L., Marsland, S., McSweeney, F.K., Wilson, D.a., Wu, C.-F., Thompson, R.F., 2009. Habituation revisited: an updated and revised description of the behavioral characteristics of habituation. Neurobiol. Learn. Mem. 92, 135-138.

Rankin, C.H., Broster, B.S., 1992. Factors affecting habituation and recovery from habituation in the nematode Caenorhabditis elegans. Behav. Neurosci. 106, 239-249.

Slabbekoorn, H., Bouton, N., van Opzeeland, I., Coers, A., ten Cate, C., Popper, A.N., 2010. A noisy spring: the impact of globally rising underwater sound levels on fish. Trends Ecol. Evol. 25, 419-427.

Slotte, A., Hansen, K., Dalen, J., Ona, E., 2004. Acoustic mapping of pelagic fish distribution and abundance in relation to a seismic shooting area off the Norwegian west coast. Fish. Res. 67, 143-150.

Stadler, J.H., Woodbury, D.P., 2009. Assessing the effects to fishes from pile driving: Application of new hydroacoustic criteria. In: Bolton, J.S. (Ed.), 38th International Congress and Exposition on Noise Control Engineering 2009 (INTER-NOISE 2009). Curran Associates Inc, Ottawa, Ontario, Canada, pp. 3580 3587.

Thompson, R., Spencer, W., 1966. Habituation: a model phenomenon for the study of neuronal substrates of behavior. Psychol. Rev. 73, 16-43.

Woodbury, D.P., Stadler, J.H., 2008. A proposed method to assess physical injury to fishes from underwater sound produced during pile driving. Bioacoust. Int. J. Anim. Sound Rec. 17, 289-291. 